\title{
From $A$ Study of $W a r$ to peace research: some criteria and strategies
}

\author{
J. DAVID SINGER \\ Department of Political Science and Mental Health Research Institute, University of Michigan
}

If Georges Clemenceau is noted for pointing out that the conduct of war is too important to be left to the militarists, it is Quincy Wright who reminds us that the analysis of war is too important to be left to the intuitionists. After years and volumes of literary speculation on the causes of international war, it was he who undertook the first systematic search for those empirical regularities which might shed some light on the origins of war among nations (Wright, 1942). ${ }^{2} \mathrm{He}$ was not, however, completely alone. At about the same time that his monumental project was getting underway at the University of Chicago, two other scholars were undertaking comparably systematic and ambitious studies of the problem. One was the sociologist Pitirim Sorokin, whose work on war is reported in Volume III of his Social and Cultural Dynamics (1937) and the other was Lewis Richardson, the physicist whose output remained largely unread until the posthumous publication in 1960 of

\footnotetext{
${ }^{\prime}$ This is a condensed and reoriented version of a paper originally prepared for the Quincy Wright Festschrift (Lepawsky, Buehrig, and Lasswell, 1971). John Goormaghtigh, Karl Deutsch, Dieter Senghaas, and Allen Whiting contributed useful comments on earlier drafts.

${ }^{2}$ Nor did he stop with the completion of this opus. As a few of his papers cited in the references make clear, he continued to reappraise and reconsider the problem almost up to the day of his death.
}

Arms and Insecurity and Statistics of Deadly Quarrels. ${ }^{3}$

In the conversion of war from a subject of speculation and propaganda to one of scientific analysis, all three of these pioneers, as well as others, have played key roles. The purpose of this paper, however, is not so much to appraise the work of the past as to suggest an orientation toward that of the future. While the need remains for a systematic appraisal and codification of existing research, and the framework proposed here could indeed be used for it, space permits only a superficial backward glance. ${ }^{4}$ The paper will concentrate, therefore, on a set of dimensions for describing, and criteria for evaluating,

\footnotetext{
'The reader's attention is called to the thorough, and extremely generous introduction to Statistics of Deadly' Quarrels, by Wright and Carl Lienau, who jointly edited this portion of Richardson's work after his death in 1953. Characteristic, too, of Wright's thoroughness and generosity are the frequent allusions to, and inclusions of, Sorokin's work in A Studv of War.

${ }^{4}$ I had originally intended to incorporate in this discussion a summary of all the known data-based findings relevant to each set of variables, but it turns out that this would extend the paper even further beyond the prescribed number of pages. I will, however, cite the most relevant of these studies, and many of them will be included in a forthcoming volume (Singer and Jones, 1971) in which some 130 or so data-based articles on international politics will be abstracted in considerable detail.
} 
social science knowledge on the causes of international war, and will conclude with some suggested strategies for picking up where Wright and his distinguished colleagues stopped. Let me emphasize at the outset that I see the pursuit of knowledge on the causes of war as a central concern of what has come to be called peace research, but by no means as the entire concern. Moreover, I have no doubts that research on war and its causes is no less legitimate, or appropriate, an object of scientific inquiry than, let us say, automobile "accidents," influenza epidemics, inventory control, or rocket launchings. This is not to ignore the problems of eventual applicability of our findings, or to deny the ignorance, taboos, and political constraints that may prevent or delay the acceptance and utilization of knowledge on the causes of war. But that is another set of problems, and while equally researchable, need not concern us here. ${ }^{5} \mathrm{My}$ hope, then, is to offer some ideas, based to a large extent on the Correlates of War project underway at the University of Michigan, which may contribute to the efficient acquisition and codification of knowledge on the causes of modern international war. To do so, I will look first at the qualitative dimensions along which such knowledge may be evaluated, and then go on to its more substantive aspects.

\section{Two Criteria: Quality and Relevance}

Whenever we seek, or claim, knowledge on the causes of war (or any other phenomena), there are two sets of criteria that need to be satisfied. The first concerns the scientific quality of the putative or anticipated knowledge, and the second concerns its explanatory relevance. Let us deal with the first briefly and then dwell upon the second at somewhat greater length.

\footnotetext{
${ }^{5}$ A relatively optimistic view is expressed in Singer (1970), while a sharply pessimistic one is in Rapoport (1970).
}

\section{THE QUALITY OF OUR KNOWLEDGE}

One possible way of evaluating the quality of social scientific knowledge is to reduce it into its component assertions or propositions, translate these (when necessary) into clear and operational language, and then ascertain where each such proposition or cluster of propositions falls along each of three dimensions. ${ }^{6}$

The first, accuracy dimension, reflects the degree of confidence which the relevant scientific community can have in the assertion at a given point in time; this confidence level is basically a function of the empirical or logical evidence in support of the proposition, but may vary appreciably both across time and among different scholars and schools of thought at any particular moment. The second dimension reflects the generality of the proposition, ranging from a single fact assertion (of any degree of accuracy) to an assertion embracing a great many phenomena of a given class. Third is the explanatory dimension: is the assertion essentially correlational or largely explanatory? With these three dimensions, we can construct some sort of epistemological profile of any proposition or set of propositions, and can classify and compare a given body of knowledge with another, or with itself over time. It should be emphasized, however, that all three dimensions are rough and merely ordinal in nature, and that there is no intention of treating them as interval or ratio scales, at least for the present.

For those of us concerned with understanding the causes of war, the objective is to move as rapidly as possible on all three dimensions.

\footnotetext{
${ }^{6}$ The position taken here is that we have something less than knowledge until it can be communicated in relatively operational form to most of the relevant intellectual community. A personal insight or vague intuition-even if it can be "understood" by others - may lead to knowledge, but does not yet constitute knowledge in the Western, scientific sense of the word.
} 
What we seek are propositions in which the most competent, skeptical and rigorous scholars can have a high degree of confidence, although they may have originally been put forth on the basis of almost no empirical evidence at all. They will be propositions which are highly causal in form, although they may have been built from, and upon, a number of propositions which come close to being purely descriptive. ${ }^{7}$ And they will be general rather than particular, although the generalizations must ultimately be based on the observation of many particular cases. From an immediate policy-oriented point of view, we may admittedly be more interested in understanding the possible causes of the next likely (and therefore, more specific) war, but my view is that the route to such understanding (and hopefully, prevention) is an indirect rather than a direct one, which must first run through an understanding of war in general. Until we can understand and explain a class of phenomena, we cannot explain a single case of that class, even though we may nevertheless do a fair job of predicting the outcome of that case and describing some of the conditions which surround it. ${ }^{8}$

'Those social scientists who take too literally the example of the physical (or even the biological) sciences will be quick to urge that the inductive road (paved as it is with small and costly blocks of evidence) is hardly the most efficient route to knowledge and that propositions deduced from some larger theory are cheaper to come by and easier to defend. True enough, but where are the social science equivalents of the theories of gravity, thermodynamics, celestial mechanics, and so forth? By even the most modest criteria, we have precious little theory from which to deduce our propositions.

${ }^{8} \mathrm{~A}$ quotation from Wright (1957) is apposite here: "A case history, if composed without a theory [sic] indicating which of the factors surrounding a conflict are relevant and what is their relative importance, cannot be compared with other case histories, and cannot, therefore, contribute to valid and useful generalizations. On the other hand, a theory, if not applied to actual data, remains uncon-
Given these criteria, let me now try to appraise very briefly the quality of the past, present, and preferred future state of our knowledge on the causes of international war. As I see it, between the establishment of the international system (circa the Treaty of Utrecht in 1713, or the Treaties of Westphalia in 1648 if one prefers the earlier date) and the pre-World War II period, there was little important change in the quality of our knowledge regarding war and its causes. Admittedly the diplomatic and military historians of that epoch gradually added to our knowledge, giving us an increasing number of simple facts; these descriptive statements, while usually of high accuracy, seldom generalized beyond one or two cases, and when they sought to embrace a number of connected variables in the search for explanation, the confidence level almost invariably decreased. ${ }^{9}$ In addition to a gradual increase in knowledge of the high confidence, but low generality and low explanatory, types, this period saw a remarkable degree of work in the form of speculative treatises on the causes of war. At a high level of generality, and seeking or claiming a considerable degree of explanatory power, these collections of assertions (based as they

vincing . . " (p. 265). And later in the same article: "Comparison would be facilitated if quantifications, even though crude, are made whenever possible" (p. 275). In a later article (1965) he very much follows his own advice.

${ }^{9}$ While disagreeing with those social scientists who hold that there is no such thing as an explanation when dealing with only a single case, I do concur that such explanations can seldom command much confidence. They may be plausible, but one can almost invariably come up with equally plausible, but incompatible, explanations. In choosing between competing explanations, we must either gather more and more detailed information on the single case, or place it into a class of cases for which a general explanation has already been developed. As a matter of scientific efficiency, the latter is much to be preferred. 
were on very few high confidence factual assertions and very few cases) could hardly command much confidence today. ${ }^{10}$ In the prescientific era, such conjectural "explanations" may have been widely accepted in some scholarly and political circles, but since the single fact assertions on which they often rested were not operationally defined and measured, and were therefore not comparable and cumulative, one may regard them today only as stimulating, albeit often original, sources of hypotheses.

The only exceptions I know which contradict the above evaluations are the scattered studies undertaken by a few nineteenth and early twentieth century economists. Because of their greater familiarity with quantitative data, operational measurement, probabilistic reasoning, and a propensity toward longitudinal and comparative analyses, several economists with an interest in the causes of war were able to add some modest knowledge of a fairly accurate, general, and explanatory sort. My impression, however, is that they were preoccupied primarily with business cycles, and only secondarily with the place of war in these cycles. "'

But despite this assistance from the economists and economic historians, it was not until the late 1930s that an important qualitative change in our knowledge of war and its causes began to take place. Spearheaded primarily by Wright, Richardson, and Sorokin, we began for the first time to fill in some of that "knowledge space" characterized by relatively high confidence and generality and in the

\footnotetext{
"Some partial listings of this voluminous literature are to be found in Wright (1935), Bernard (1944), Bouthoul (1951) and Richardson (1960a).

"Among these are: Secerov (1919), Schumpeter (1939), and Frisch (1949). Only the first of these is devoted primarily to the search for an explanation of war. Another economist, Bloch (1903), sought to demonstrate how a variety of economic, demographic, and technological factors would soon put an end to war.
}

middle-to-high sector on the explanation axis. Following the lead of these pioneers-the first two of whom continued this work in the postWorld War II period--the peace research movement of the late 1950s and the 1960s begun to generate inputs at many points along all three of our evaluative dimensions. We will return to this in the concluding section.

\section{THE RELEVANCE OF OUR KNOWLEDGE}

No matter how high the quality of our knowledge on the accuracy, generality, and explanatory dimensions, it may still be of no value in understanding - or reducing the incidence of-war. It must, in the final test, be relevant to the problem we seek to solve. A well-integrated body of true and general propositions may explain something other than how wars begin, escalate, or endure. But whereas many scientists might readily agree as to the quality of a given body of knowledge, the criteria for appraising its relevance are less obvious. Thus, rather than go on a private epistemological excursion into such criteria, let me turn to a consideration of those variables and models which - for one researcher at least-seem most relevant to the problem which so engaged Quincy Wright and those of us who follow in his footsteps.

\section{The Search for Explanatory Variables}

\section{THE OUTCOME VARIABLE: MEASURING THE INCIDENCE OF WAR}

In order to fit existing or anticipated knowledge into any explanatory framework and then evaluate the extent to which it correlates with, predicts, or accounts for the incidence of war, it is absolutely imperative that we first attend to that phenomenon whose occurrence we hope to explain. That is, if we hope to explain and account for the incidence of war, we must first discover: (a) what its incidence has been, and 
(b) what conditions and events correlate with the presence of, absence of, and magnitude of war. As obvious as this statement may be, only a fraction of those who seek to understand and explain the causes of war have ever bothered to generate such data or to utilize that of those who did. In addition to Wright himself, the only others who have tried to provide an operational description of the incidence of international war over any appreciable spatial and temporal domain are Sorokin (1937), Richardson (1960a), Urlanis (1960), and Singer and Small (1971). Let me summarize and compare several of these efforts.

First of all, Wright sought to identify for the period 1480-1940 "all hostilities involving members of the family of nations, whether international, civil, colonial, or imperial, which were recognized as states of war in the legal sense, or which involved over 50,000 troops." While his population of international wars is not complete, and his inclusion criteria are occasionally idiosyncratic, he produced (1942) the first definitive catalogue for the post-medieval epoch. And while Wright did not gather data on the casualties sustained in these wars, he did identify the major protagonists, the dates, and the general outcome for each of the 278 wars which fell into his net.

At about the same time, but apparently unbeknownst to one another, Sorokin and Richardson embarked on a similar enterprize. While Wright's listing covered about four centuries, Sorokin (1937, vol. 3) sought data on the incidence of war during the long period from the fifth century B.C. up to 1925 . He was less interested in identifying the specific wars or their dates or protagonists than he was in estimating, for quarter-century periods and longer, the approximate number of wars, army sizes, numbers killed, and so forth. Given his theoretical purposes (1938), such figures were probably adequate, but for any detailed analysis of shorter-run fluctuations in a more restricted spatial and temporal setting, they are much too gross.
Covering a shorter time span than either Wright or Sorokin, but in considerably greater detail, Richardson (1960a) sought-not quite successfully-to identify all wars since 1820 in which more than 315 (the equivalent of his $\log _{10}$ magnitude of 2.5 ) fatalities were sustained. For each, whether civil or international, he attempted to identify not only the protagonists and dates, but most important, to make an accurate estimate of the battle-connected fatalities which eventuated from each such "deadly quarrel". Moreover-and at this point he became very pre-operational-he sought to specify the causes of each war on the basis of the military and diplomatic histories. ${ }^{12}$

Finally ${ }^{13}$ there is the Singer and Small compilation which will soon appear under the title The Wages of War, 1816-1965: A Statistical Handbook (1971). Inspired by, and largely building upon the Wright and Richardson efforts, it represents the most comprehensive, operational and carefully compiled set of

\footnotetext{
${ }^{12}$ Several secondary analyses of Richardson's war estimate data have been published, seeking some chronological pattern in the ebb and flow of war, but not to account for that pattern in the explanatory sense; see Weiss (1963) and Denton (1966).

${ }^{13}$ Despite the prodigious work that obviously went into it, one cannot put the Urlanis (1960) compilation into the same class as the others. His coding rules are often unstated, seldom consistent from one table to another, and produce figures that are not compatible with one another; nor does he include and exclude wars according to any compelling and explicit criteria. Somewhat similar criticisms must be made of the recent report of the Institut Français de Polemologie (1968); it presents many figures over a long period of time, but gives not a single specific citation (a few authors are mentioned, but no sources) nor any coding or scaling rules.

There are, on the other hand, several careful and apparently accurate compilations which cover rather limited domains; among these are Harbottle (1904), Bodart (1916), and Dumas and Vedel-Peterson (1923). Finally, a devastating description of how a journalist's idle speculation on the incidence of war became accepted data in some of the "scholarly" literature is found in Haydon (1962).
} 
data available for the time period. It makes no effort to get at the correlates or causes of the ninety-three wars which are reported, but rather seeks a full and detailed description of this outcome variable, measured in terms of the frequency, magnitude, severity, and intensity - plus trends and distributions-of several types of international war. The data are organized initially by individual wars, but are then aggregated in order to show the distribution of different types of wars among different classes of nations for a variety of spatial and temporal domains. Our hope is that these materials will encourage the sort of rigorous and meticulous research which was hitherto not possible.

\section{CLASSIFYING THE PREDICTOR VARIABLES}

The number and variety of schemes for classifying and sorting out the possible causes of war is quite large, and the typology selected depends not only on a range of scientific considerations but upon many extra-scientific ones: nationality, age, sex, basic personality, education, prior research experiences, and not surprisingly, the fads and fashions of the moment as exemplified by those who employ us to teach, who finance our research, and who otherwise are in a position to pass judgment on our plans and our performance. In this section I will discuss what appears to be one of the more prevalent types of scheme, argue its inadequacies, and then move on to an alternative which seems to provide a satisfactory means of formulating substantive propositions, putting them to the empirical test, acquiring new knowledge, and codifying what we do know, think we know, and need to know.

The most widely used taxonomy is one which divides the alleged or potential explanatory variables into the standard disciplinary categories: political, economic, psychological, and sociological; some might include ideological factors under the political or the psycho- logical categories, and technological factors under the sociological category. My objection to this sort of scheme is partly a function of its inherent inadequacies, and partly a response to the work of those who adhere to it.

Taking the latter grounds first, one is struck by the frequency with which many scholars move quickly from such an itemization to a concentration on just one of the categories, and proceed to "explain" the incidence of war almost exclusively in terms of that single cluster of variables. And, to nobody's surprise, the academics among us usually tend to select the variables of their own discipline. If such parochialism were to lead to the systematic collection of data for one or more variables in, for example, the economic or sociological sector, and then to the search for correlations between them and the onset of war, one could hardly complain. Such a procedure would enhance that critical mid-region of high confidence and high generality in our knowledge space. What it all too often leads to, however, is nothing but further speculation and conjecture. To the extent that single facts are brought to bear, they are neither representative nor operational, but a result of conscious or unconscious ransacking of the past in search of those few cases which tend to support the author's theoretical point of view.

My a priori objection is that no coherent model of an essentially explanatory nature can emerge from so restricted a set of independent and intervening variables. To put it simply and quite conventionally, if it is governments which decide on war and then manage its prosecution, no explanatory model which excludes political phenomena can be satisfactory. Even if we found that a certain cluster of economic or sociological or psychological variables were to correlate with, and account for a large percentage of the variance in, the frequency of, or magnitude of war in a given spatial-temporal domain, we would still be some distance from a satisfactory explanation 
of war. Just as I would argue that no explanation is scientifically adequate if it fails to account for the human perceptions and responses which link up the allegedly causal sequence, no explanation of war is adequate unless it specifies the decision process which links up the "objective conditions" with the military events themselves. There are, of course, many other formulations, and any one familiar with the "causes of war" literature will appreciate not only their diversity, but the ingenuity, learning, and dedication which they represent. However, rather than try to go over a great deal of old ground and summarize those formulations here, let me proceed to the delineation of a proposed alternative, in the context of a discussion on the substantive evaluation of our knowledge, possessed or anticipated.

In presenting this framework, it is well to keep in mind the demands that it should be able to satisfy. First it should be built around concepts that are as familiar as necessary, consistent only with the requirement that they reveal rather than conceal what our hunches and knowledge lead us to believe will be the most powerful explanatory variables. At this juncture, this is largely a matter of trained intuition. This brings us to the second requirement-the ability of the scheme to embrace and codify, in a comparable and cumulative fashion, the most promising research which has so far been undertaken, as well as that which seems to lie ahead. Closely related is the need for it to be compatible with the concepts and findings of related disciplines. Third, it must permit the development of variables which are both valid and reliable, and, to satisfy the latter, the key constructs need to be as operational and quantifiable as possible, rather than vague and ephemeral. If a taxonomy is to contribute to the acquisition and codification of evidence which is not only theoretically promising, but methodologically cumulative and comparable, these are the minimal criteria. Hopefully, the scheme which follows will turn out to satisfy these criteria. ${ }^{14}$

\section{APPRAISING THE PREDICTOR VARIABLES}

Since war is made, contemplated, and conducted by, and on behalf of, human beings organized into a variety of social entities, and is not made by relationships or roles or system properties (not to mention "social forces"), it makes perfect sense to build our taxonomy around those entities, however transitory and/or amorphous they may turn out to be. All sorts of social groups can and do wage war, but since our concern for the present is with international war, we can confine ourselves to the most relevant sub-national, national, and extra-national groups here, and neglect those of peripheral interest. These social groups range at the sub-national level from the family and primary work group up through all sorts of secondary associations to political parties, government agencies, legislatures, cabinets, and armies. When many such groups-at various levels of analysis and covering various functional sectors - are relatively unified and coordinated within a national territory, the resulting coalition may be called a nation. The nation or nation-state is the dominant unit of the contemporary international system, but for centuries before the emergence of that system, man was organized in many other types of social organizations. As other more effective groupings develop and attract the loyality of their members, that pattern may be renewed, and it will be increasingly appropriate to refer to the global, rather than the international system. In any event, the nation is the major partici-

\footnotetext{
${ }^{14}$ One imaginative scheme, while less than operational, covers several levels of analysis, from the intra-psychic to the inter-national, and almost all sectors of human activity; see Deutsch and Senghaas (1969).
} 
pant in modern international war, even though the probability of any such war, and its outcome, may well be more influenced by the various sub-national and extra-national groupings with which the nation shares the current world stage.

Every social unit may, in turn, be described in terms of three sets of attributes or properties: physical, structural, and cultural. Among the physical attributes are those of a geographic, technological and demographic nature. Among the structural attributes are the institutions and configurations normally associated with the labels: "political", "economic", and "sociological". And among the cultural (or better, psychocultural) attributes are the perceptions, preferences, and predictions of those individuals who comprise the entity (Singer 1968b).

Following the unfortunate tendency of the practitioners themselves, many scholars - be they oriented toward the conjectural or the correlational-have sought the causes of war in this very restricted set of variables. Certain nations in certain periods are labeled as aggressive or war-like (which may not be equivalent to war-prone) and their dominant structural, cultural, or physical attributes are assigned high explanatory status. Even though there has been little research leading to propositions of this sort in the high confidence, high generality, and correlational region of our knowledge space, these variables do not deserve to be jettisoned because of their propagandistic taint. While most of the inquiries into the effect of physical, structural, and cultural attributes on a nation's war-proneness suggest that they have little predictive or explanatory power (Cattell and Gorsuch, 1965; Rummel, 1968; Tanter, 1966; and Haas, 1968) a recent secondary analysis (Wilkenfield, 1968) points in the opposite direction; and Richardson (1960a) also seems to have uncovered some associations between the nations' attributes and their war-proneness.
In my view, bi-variate and multi-variate analyses using attribute variables should continue, on the assumption that, while helping to clear away the debris of political folklore, they will eventually fit into analyses which look at other classes of independent and intervening variables at the same time.

Another such class of variables is that of relationships between and among the nations and other entities in the system. These are of two types: comparisons and connections. The comparative type of relationship permits us to examine the similarities or differences between and among entities in order to see whether they help account for the war-proneness of particular pairs. Does it turn out that nations which are close together on such attributes as political ideology, or far apart on level of industrialization, are less war-prone than pairs whose attributes match in another fashion? The evidence here is also quite sparse, and the projects which have given greatest attention to this set of variables so far (Richardson, 1960a, and Rummel, 1963), show very mixed results. Shifting to the second type of relationshipthat of a connective nature-we may profitably ask to what extent we can predict the frequency and magnitude of war for a given nation if we know something about its links and bonds to other nations, or to the warproneness of a pair of nations on the basis of the interdependence and connections between them.

As with national attributes, the available evidence on relationships is both scanty and mixed. For the pre-World War II period, Wright developed some "distance" indicators that predicted well which pairs of nations would be at war against, and alongside of, one another (1942, App. XLIII). And Richardson found some association between the warproneness of a pair and its linguistic and religious differences, but little association between economic inequality and such warproneness; as to connective relationships, he 
found geographical contiguity to be an important predictor, prior military hostilities to be moderately important, and prior wartime alliances to have had little effect (1960a, Chaps. 5 and 6). Also relevant is the Singer and Small finding (1968) of a strong correlation between the number of alliance bonds a nation has and the amount of war it subsequently experiences. In sum, there seems to be a growing interest in relational variables as predictors to war (as well as to other phenomena), and my suspicion is that Wright was correct in urging us to attend to such comparisons and connections. Once more, though, the explanatory power of such variables will be considerably enhanced when they are combined with other sets of variables.

Let me shift back to attributes of social systems again, but at the international or global, rather than national, level of analysis. This sequence makes sense inasmuch as many of the international system's attributes, especially the structural ones, are based on the observation of relationships among its members. While there is a growing body of conjectural literature on the correlation between system properties and the incidence, or probability of war (Deutsch and Singer, 1964; Waltz, 1959), there is very little evidence on the strength and direction of this association; nor has there been much effort to develop operational measures of such variables. ${ }^{15}$

The problem is further confounded by the fact that some see war as a function of the system's inherent and constant properties, while others search for the association between fluctuations in such properties and

${ }^{15}$ Some data and measures of the attributes of the international system over the past century and a half are in Singer and Small (1966a, 1966b, 1968), and Wallace and Singer (1970). Also see the promising measures and data reported in Russett (1967), the pioneering effort of Deutsch et al. (1957), and the Princeton University project on "security communities." the fluctuation of war. Using the latter orientation, we found a very discernible negative correlation between alliance aggregation and subsequent war in the nineteenth century, and a stronger, but positive one, in the twentieth (Singer and Small, 1968); we also found practically no correlation between the amount of inter-governmental organization in the system and subsequent warfare (Singer and Wallace, 1970). ${ }^{16}$ As to physical properties of the system, Rummel (1961) found some positive associations, as well as several negligible ones, between technological innovations and war. Regarding the perhaps most important system properties, psychocultural properties, there is almost no evidence on the extent to which shifts and fluctuations in the distribution of perceptions, perferences, and predictions may affect the frequency and magnitude of war. This set of variables, like the others already mentioned, has also received little empirical attention of a correlational nature, yet it is difficult to see much progress in understanding the causes of war until it, too, has been included in some systematic empirical investigations. ${ }^{17}$

So far, I have mentioned no behavioral variables and have focused solely on system or actor attributes (physical, structural, and cultural) and on relationships (comparative and connective) between and among actors. Some will contend that this represents an unfortunate emphasis and that the "real" causes of war will be found in the decisions of political

\footnotetext{
${ }^{16}$ Also turned up in this inquiry was the strong correlation between the amount of war ending in any half-decade and the amount of new Inter-governmental Organization established in the following decade, suggesting that even though the historical effects of such organization on the incidence of war have not been impressive, public or private elites may believe otherwise.

"See, for some promising early efforts, such Stanford University studies as Holsti, North, and Brody (1968), and Zinnes (1968). For a systematic discussion of the problem, see Waltz (1959).
} 
elites and the resulting actions of their nations. While fully concurring that an "ecological" theory of war would be incomplete at best, I would urge that serious attention to these attributes and relational variables is absolutely essential. ${ }^{18}$ To look at behavioral events alone, or as parts of interaction sequences, is to court disaster unless they are examined along with-and in the context of the physical, structural, and cultural setting within which they occur.

The problem is three-fold. First, as suggested earlier, governmental decisions and behavior represent the intervening variables between a set of ecological incentives and constraints (domestic and global) on the one hand, and war or no war as the outcome of conflict, on the other; they can only be understood in that sort of context. Second, until we can get at the discrepancies (if any) between the objective incentives and constraints and the way in which they are perceived, we will be far from understanding the behavior which leads toward or away from war. Third, until certain of the key ecological variables are identified and their own explanatory power ascertained, we will never know exactly how much control remained in the hands of the decision-makers and how much of the variance is accounted for by their behavior. One of the interesting differences between Wright and Richardson is that the former's work (1942, 1957, and 1965 particularly) seems to follow strongly from this point of view, while the bulk of the latter's theoretical efforts (1960b) focuses almost exclusively on behavioral and interactional phenomena. Some who have followed up Richardson's work on arms races have, happily, paid more attention to the

\footnotetext{
${ }^{18}$ This view is quite consistent with that which distinguishes between the remote and the immediate, the fundamental and the inciting, or the institutional and the behavioral causes of war as found in much of the speculative literature.
}

ecological setting within which such interaction sequences occur (Smoker, 1963). ${ }^{19}$

That there has been little operational data gathered on behavioral and interactional phenomena is not surprising; whether as outcome or as predictor variables, and whether related to war or anything else, it is extremely difficult to identify a population of behavioral events, draw a useful sample, and then classify or scale them. Despite that difficulty, however, a number of recent efforts suggest that the problems are far from insurmountable. First, there are the above-noted studies of the Stanford University project, focusing on the behavioral (as well as psychological) phenomena which characterized the period leading to World War I, the Cuban missile crisis, and other conflicts (Holsti, 1965; Holsti, North, and Brody, 1968; Zinnes, 1968; and North and Choucri, 1969). There are also the University of Southern California studies, examining the Berlin and Taiwan Straits crises of the post-World War II period (McClelland, 1968, and McClelland and Hoggard, 1969). Also advancing our capacity to describe and analyze inter-national conflict sequences in operational terms are Corson (1970), Azar (1970), and Burrowes (1969). More comprehensive, covering all pre-war conflicts in the system since the Congress of Vienna, but now only at the pre-test stage, is the typology and its rationale reported in Leng and Singer (1970). ${ }^{20}$

Appreciating the difficulty of coding and scaling the behavior and interaction of

\footnotetext{
${ }^{19} \mathrm{Also}$ in the behavioral sector is an oft-cited article (Abel, 1941) which purports to have "found" that tensions, misperceptions and other non-rational factors have seldom been important in the decision to go to war; rather, the study concludes that such decisions are taken cooly and well in advance of the onset of hostilities. However, there is not a shred of operational evidence reported, nor did a letter of inquiry to the author produce such evidence.

${ }^{21)}$ For a thoughtful treatment of the ways in which complex diplomatic moves may be measured, see Moses et al. (1967).
} 
national governments during conflicts, a number of peace researchers have shifted their attention to the "simulate" world. Such simulations take two basic forms: man-machine and all-machine (computer) simulation. While it is difficult to take the former type of study very seriously as a technique of discovery, these man-machine simulations have probably been valuable in the heuristic, suggestive, sense of the word. ${ }^{21}$ More promising in its ultimate theoretical and policy payoffs, however, will be the computer simulation, in which we can more fully manipulate and examine the historical unfolding of the "real" world, as well as the world of the past (or of the future) as it might have unfolded. We will return to this research strategy in the conclusion.

To summarize this section, then, my view is that no one cluster of variables is likely to play a dramatic role as we gradually discover the causes of international war. It will almost certainly turn out that certain attributes do indeed make some nations more war-prone than others, but it will probably also turn out that these attributes are the ones which shift over time, making the stage of development or certain short-range perturbations more critical than such relatively fixed attributes as language or religion or ethnicity. I would, on the other hand, expect that these attributes-in order to exercise any consistent and powerful effect-have to interact with certain relational variables and with the attributes of the international system at the moment. A nation must, in a sense, be in the "right" setting if it is to get into war. Finally, there is little doubt that all of these ecological factors will have to be taken into account, and controlled for, if we are ever to understand the dynamic processes of behavior and interaction which are

\footnotetext{
${ }^{21}$ The classical statement is in Guetzkow et al. (1963), and one of the more thorough experiments and reports is in Brody (1963); my reservations are in Singer (1965).
}

so large a part of conflict. To talk about decision-making, political choice, strategy and the like in the absence of well-mapped environmental limits and opportunities is to exaggerate (or perhaps even underestimate) the autonomy and the power of those who act within such an environment. ${ }^{22}$

\section{Conclusion}

Let me try now to bring together the two sets of criteria which have been discussed separately, and on the basis of such a convergence see whether there is any one best research strategy for those of us seeking the causes of international war. If not, are there at least some fairly clear priorities that emerge? Now some will argue, in true academic tradition, that there is no one best way to do anything, that each of us should pursue his own line of inquiry, doing that which he does most competently and comfortably. And then, by some cosmological magic, all of these separate bits of knowledge will fall neatly into place, culminating in a single coherent theory.

While we need not set up a Manhattan Project or a PERT system (used to coordinate the discrete phases of the Polaris missile submarine project), it is naive to expect that the disparate frameworks, vocabularies, and empirical domains now represented in peace research will inevitably mesh and reinforce one another. At the same time, it would be presumptuous for any one scholar--and premature at this juncture-to spell out a single specific research program. Not only is the causes of war question merely one aspect of peace research, but the quality and the relevance of our knowledge on this one question are far from adequate as a basis for predicting the most efficient research path.

Having said this, however, let me propose

\footnotetext{
${ }^{22}$ The most systematic treatment of this problem remains Sprout and Sprout (1965).
} 
and defend a general strategy which seems well-suited for the acquisition and codification of knowledge on the causes of international war. First, certain kinds of conjectural work could easily be dispensed with "for the duration." I refer to the sort of essay in which some single-cause "theory" is propounded, most often in terms of a biological, psychoanalytical, or economic variable. If one is persuaded that his propositions make sense, let him put the independent variable(s) in operational form, gather the necessary data, and see how the resulting time series correlate with the war data which are now available. If there is little or no established association, the enterprise will (if conducted competently) have nevertheless made some contribution to our knowledge. Even negative findings, while somewhat less valuable (since they are more probable and therefore convey less information), are very much worth turning up. I reject conjectural work on single cause ideas not only because I am convinced that no single variable will ever account for enough of the variance to justify yet another essay on the subject, but because just about every single cause conjecture has already been made. If a fairly thorough search of the literature reveals no prior discussion of the alleged causal factor, then a brief essay may well be merited, especially if it leads to an empirical investigation.

On the other hand, there is plenty of room for multi-variate conjecture, especially if the variables are stated in relatively operational form and if the relationships among them are explicitly spelled out in terms of an integrated model and hypothesized causal sequences. That is, despite the obvious paucity of evidence, and the apparent surfeit of speculation, there is still great need for pre-empirical, but scientific thinking, and the generation of hypotheses and models which could then be checked against evidence. But the payoffs in this speculative sector will almost certainly come from scholars who are at home in scientific method and who not only know how to conduct rigorous research, but how to analyze a problem and the existing evidence in order to set up the really critical, rather than routine, experiments. ${ }^{23}$ Furthermore, my prediction is that the really critical research designs will come from scholars who are relatively at home in several of the social science disciplines as was Wright (1955), and who think in general systems terms.

Having said all of this, however, there is little question in my mind that the greatest need is in the correlational sector. Our desperate requirement now is a data and findings base from which we may proceed to the systematic testing of a multiplicity of plausible explanations of war. Even as we wait and hope for the brilliant insight which may unlock the mystery, three points must be kept in mind. First, even if that brilliant conjecture is forthcoming, we will not recognize it, and should not believe it, until we have seen the evidence; and the more data we generate, the easier it will be to "check it out" when it comes along. Second the more solid data at hand, and the more bi-variate and multi-variate analyses available, the more efficiently and persuasively can we look into and reject hunches or hypotheses that are inadequate. Conversely, in the absence of such data and the associated correlational analyses, the theoretical break-

\footnotetext{
'While experiments are generally associated with laboratory research in the physical or biological sciences, or in psychology and sociology, it should be noted that experiments may be conducted in two other settings as well. There is the "field experiment" in which the researcher waits for, or stimulates, the experimental condition in the natural setting, and the "historical experiment", in which he Ireats the unfolding of past events as if he did not know how they would turn out. An excellent discussion of the critical type of experiment, applicable to the field and historical, as well as to the laboratory setting, is Platt (1964).
} 
through may be rejected because it is unconventional, implausible, or politically distasteful; just as bad, scientifically indefensible explanations may be embraced because they are plausible or acceptable, and because there is little evidence to refute them. Finally the more data a creative social scientist has ready at hand, the more likely he is to come up with the critical insight; nothing is as suggestive of hypotheses as data and correlational matrices to a scholar who is not only thoughtful, but at home with statistical materials.

The view taken here is that the right combination of conjectural and correlational research could bring us close to a causal theory of war within a few years. Imaginative but disciplined conjecture can prevent us from embarking on a decade or more of mindless empiricism, and the gradual buildup of comparable and cumulative correlational findings can provide us with a growing knowledge base against which our conjectures may be tested. The idea, of course, is that we must move toward the construction and verification of multi-variate causal models just as quickly as our data and ideas permit. ${ }^{24}$ These models, in turn, may be checked out in two ways. The first and most relevant is vis-a-vis the empirical realities of the international system as the tides of war ebbed and flowed.

But almost as important, as our models

\footnotetext{
${ }^{24}$ In this connection, the incremental nature of empirical research must be emphasized. This means that the first scholar to examine the correlations between (let us say) international organization and war cannot be expected to look at every single type of organization in his opening study, but must restrict himself to a well-defined subset thereof. He or others may then follow up the original work by either including certain additional organizations or using a more refined breakdown of those which had originally been lumped together. In this way, we gradually improve the validity of our measures while moving toward increasingly sophisticated sets of models, and toward findings which are high on the accuracy, generality, and explanatory axes.
}

improve and our data and correlational bases expand, is the resort to computer simulations. as suggested earlier. Our research has turned up 93 international wars during the past century and a half, most of which were preceded by conflicts and crises. From a humanitarian point of view, that may have been 93 wars too many, but from a scientific point of view it was too few. That is, not every combination of factors that could have occurred did indeed occur in actuality, and we therefore cannot be certain whether a particular combination of factors might have led to war, had that combination occurred. And conversely, for those combinations which did occur and were followed by war, we probably will not find enough historical cases in which all but one of the factors were the same and from which war did not ensue.

The virtue of a computer simulation is that it permits us to recreate such events and cases in a large variety of combinations, and if we know enough about the relations between and among certain variables in certain combinations, we can use that knowledge to simulate what would (or might) have happened had the combination been sufficiently different. In essence, a computer simulation is little more than an operational statement of one's theory, or alternative theories, in which different magnitudes of the separate variables are tried out in order to ascertain the effect, singly and in combination, of many differing magnitudes and rates of change in these variables. With it, we can discover, by means of sensitivity analysis of the model, at which thresholds these changes are likely to have critical effects. If the model itself is relevant, the variables are critical, and the data inputs are sound, such a simulation series can eventually add to our knowledge in a dramatic way. ${ }^{25}$

\footnotetext{
${ }^{27}$ In my judgment, we have barely begun to realize these possibilities, but promising starts are in
} 
In sum, then, the view here is that international war is a problem as inherently researchable as most others we have faced, and that as our research improves in quantity, quality, and relevance, we can acquire and codify sufficient knowledge to be able to explain its presence, absence, or magnitude under a variety of conditions. Whether such knowledge will be applicable to conflicts and crises of the future, it is too early to tell, but in principle, it should be. And whether such knowledge will be put to use is, of course, another question entirely and one which also merits some modest research attention in the interim. If we can continue to carry on where Wright and his fellow pioneers left off, we may yet build the most valuable applied science that man has ever known.

\section{REFERENCES}

Abel, Theodore. The element of decision in the pattern of war, American Sociological Review, 1941, 6, 853-59.

Alker, Hayward, and Ronald T. Brunner. Simulating international conflict: a comparison of three approaches, International Studies Quarterly, 1969, 13 (1, March), 70-110.

Azar, Edward. Analysis of international events, Peace Research Reviews, 1970, 4 (1, Nov.).

Bernard, Luther S. War and its Causes. New York: Holt, 1944.

Bloch, Jean de. The Future of War. Boston: Ginn, 1903.

Bobrow, Davis, and Judah Schwartz (eds.). Computers and the Policy Making Community: Applications to International Relations. Englewood Cliffs, N.J.: Prentice-Hall, 1968.

Bodart, Gaston. Losses of Life in Modern Wars. Oxford: Clarendon, 1916.

Milstein and Mitchell (1969), and Bremer (1970); two useful sets of discussions are Bobrow and Schwartz (1968), and Coplin (1968), and a rigorous critique is in Alker and Bruner (1969). Representative of the more ambitious computer simulations in economics and urban studies, respectively, are Orcutt (1961) and Forrester (1970).
Bouthoul, Gaston. Les Guerres: Elements de Polemologie. Paris: Payot, 1951.

Bremer, Stuart. National and international systems: a computer simulation. East Lansing: Michigan State University, doctoral thesis, 1970.

Brody, Richard. Some systemic effects of the spread of nuclear weapons technology: a study through simulation of a multi-nuclear future, Journal of Conflict Resolution, 1963, 7 (4, Dec.), 663-753.

Burrowes, Robert. Conflict and cooperation within and between nations: Israel, the United Arab Republic and the major Arab states of South West Asia, 1949-1969. New York: American Political Science Assoc., 1969.

Cattell, Raymond, and Richard Gorsuch. The definition and measurement of national morale and morality, Journal of Social Psychology, 1965, 67 (1), 77-96.

Coplin, William D. (ed.). Simulation in the Study of Politics. Chicago: Markham, 1968.

Corson, Watter. Conflict and cooperation intensity in East-West relations. Cambridge, Mass.: Harvard University, doctoral thesis, 1970.

Denton, Frank. Some regularities in international conflict, 1820-1949, Background, 1966, 9 (4), 283-96.

Deutsch, Karl W., et al. Political Community and the North Atlantic Area. Princeton, N.J.: Princeton University Press, 1957.

$\longrightarrow$, and Dieter Senghaas. Toward a theory of war and peace: propositions, simulations and realities. New York: American Political Science Assoc., 1969.

$\longrightarrow$, and J. David Singer. Multipolar power systems and international stability, World Politics, 1964, 16 (April), 390-406.

Dumas, S., and K. Vedel-Peterson. Losses of Life Caused by War. Oxford: Clarendon, 1923.

Forrester, Jay W. Urban Dynamics. Cambridge, Mass.: MIT Press, 1969.

Frisch, Ragnar. Elements of the Theory of Business Cycles. Oslo, Norway: Aschehoug, 1947. In Norwegian.

Guetzkow, Harold, et al. Simulation in International Relations. Englewood Cliffs, N.J.: Prentice-Hall, 1963.

Haas, Michael. Societal approaches to the study of war, Journal of Peace Research, 1965, (4), 307-23.

- Social change and national aggressiveness, 1900-1960. In J. David Singer (ed.), Quantitative International Politics. New York: Free Press, 1968.

Harbottle, Thomas. Dictionary of Battles from the 
Earliest Date to the Present Time. London: Sonneschein, 1904.

Hart, Hornell. Depression, war and logistic trends, A merican Journal of Sociology, 1946, 52, 112-22.

Haydon, Brownlee. The Great Statistics of War Hoax. Santa Monica, Calif.: RAND Corp., 1962.

Holsti, Ole. The 1914 case, American Political Science Review, 1965, 59, 365-78.

tion and action in the 1914 crisis. In J. David Singer (ed.), Quantitative International Politics. New York: Free Press, 1968.

Institut Francais de Polemologie. Periodicité et intensité des actions de guerre, 1200-1945, Guerres et Paix, 1968, (2), 20-32.

Leng, Russell, and J. David Singer. Toward a multi-theoretical typology of international behavior. Ann Arbor: University of Michigan, Mental Health Research Institute, April 1970.

Lepawsky, Albert, Edward Buehrig, and Harold Lasswell (eds.). International Law, Politics, and Organization. New York: Appleton-CenturyCrofts, 1971 (in press).

McClelland, Charles. Access to Berlin: the quantity and variety of events. In J. David Singer (ed.), Quantitative International Politics. New York: Free Press, 1968.

interactions among nations. In James $\mathbf{N}$. Rosenau (ed.), International Politics and Foreign Policy. New York: Free Press, 1969.

Milstein, Jeffrey, and William Mitchell. Computer simulation of international processes: the Vietnam War and the pre-World War I naval race, Peace Research Society Papers, 1969, 12, 117-36.

Moses, Lincoln, et al. Scaling data on inter-nation action, Science, 1967, 156 (May), 1054-59.

North, Robert, and Nazli Choucri. The determinants of international violence, Peace Research Society Papers, 1969, 12, 33-63.

Orcutt, Guy H., et al. Microanalysis of Socioeconomic Systems: A Simulation Study. New York: Harper, 1961.

Platt, John R. Strong inference, Science, 1964, 146 (Oct.), 347-53.

Popper, Karl. The Logic of Scientific Discovery. London: Hutchinson, 1959.

Rapoport, Anatol. Can peace research be applied?, Journal of Conflict Resolution, 1970, 14 (2, June), 277-86.

Richardson, Lewis F. Statistics of Deadly Quarrels, Chicago: Quadrangle, 1960a. Quincy Wright and Carl Lienau (eds.).

- Arms and Insecurity. Chicago: Quadrangle, 1960b. Nicolas Rashevsky and Ernesto Trucco (eds.).

Rummel, Rudolph. Technology and war: a correlational analysis. Honolulu: University of Hawaii, master's thesis, 1961.

Dimensions of conflict behavior within and between nations, General Systems, 1963, 7.

. The relationship between national attributes

and foreign conflict behavior. In J. David Singer (ed.), Quantitative International Politics. New York: Free Press, 1968.

Russett, Bruce. International Regions in the International System. Chicago: Rand McNally, 1967.

Schumpeter, Joseph. Business Cycles. New York: McGraw Hill, 1939.

Secerov, Slavka. Economic Phenomena before and after War. London, 1919.

Singer, J. David. Data-making in international relations, Behavioral Science, 1965, 10, (Jan.), 68-80.

- (ed.). Quantitative International Politics: Insights and Evidence. New York: Free Press, $1968 \mathrm{a}$.

- Man and world politics: the psycho-cultural interface, Journal of Social Issues, 1968b, 24 (3, July), 127-56.

- Knowledge, practice, and the social sciences in international politics, Annals of American Academy of Political and Social Science, 1970, (December), 137-49.

- - and Susan Jones. Beyond Conjecture: DataBased Findings in International Politics. Chicago: Peacock, 1971 (forthcoming).

status ordering of the international system: 1815-1940, World Politics, 1966a, 18 (2, Jan.), $236-82$.

—. - Formal alliances, 1815-1939: a quantitative description, Journal of Peace Research, 1966b, (1), 1-32.

- — N W National alliance commitments and war involvement, 1815-1945, Peace Research Society Papers, 1967, 5, 109-40.

- - Alliance aggregation and the onset of war, 1815-1945. In J. David Singer (ed.), Quantitative International Politics. New York: Free Press, 1968, 247-86.

- _ - _. Formal alliances, 1816-1965: an extension of the basic data, Journal of Peace Research, 1969, 3, 257-82.

-, - Wages of War, 1816-1965: A Sta tistical Handbook. New York: Wiley, 1971 (forthcoming).

$\longrightarrow$, and Michael Wallace. Inter-governmental organization and the preservation of peace, 
1816-1965: some bivariate relationships, International Organization, 1970, 24 (3, Summer), 52047.

Smoker, Paul. A mathematical study of the present arms race, General Systems, 1963, 8, 51-59.

Sorokin, Pitirim. Social and Cultural Dynamics. New York: American, 1937, vol. 3.

A neglected factor of war, American Sociological Review, 1938, 3 (4, Aug.), 475-86.

Sprout, Harold, and Margaret Sprout. The Ecological Perspective on Human Affairs with Special Reference to International Politics. Princeton, N.J.: Princeton University Press, 1965.

Tanter, Raymond. Dimensions of conflict behavior within and between nations, 1958-1960, Journal of Conflict Resolution, 1966, 10 (1, March), $41-64$.

Urlanis, Boris T. Wars and the Population of Europe. Moscow: Government Publishing, 1960. In Russian and Czech.

Wallace, Michael, and J. David Singer. Inter-governmental organization in the global system, 1816-1964: a quantitative description, International Organization, 1970, 24 (2, Spring), 239-87.

Waltz, Kenneth. Man, the State and War. New
York: Columbia University Press, 1959.

. The stability of a bipolar world, Deadalus, 1964, 93, 881-909.

Weiss, Herbert. Stochastic models for the duration and magnitude of a deadly quarrel, Operations Research, 1963, l1, 101-21.

Wilkenfield, Jonathan. Domestic and foreign conflict behavior of nations, Journal of Peace Research, 1968, (1), 56-69.

Wright, Quincy. The Causes of War and the Conditions of Peace. London: Longmans, Green, 1935.

. The Study of War. Chicago: University of Chicago Press, 1942, 1965.

The Study of International Relations. New York: Appleton-Ceritury-Crofts, 1955.

Design for a research proposal of international conflict . . . , Western Political Quarterly, 1957, I0, 263-75.

- The escalation of international conflicts Journal of Conflict Resolution. 1965, 9. (4, Dec.), 434-49.

Zinnes, Dina. The expression and perception of hostility in prewar crisis: 1914. In J. David Singer (ed.), Quantitative International Politics. New York: Free Press, 1968. 